\title{
Analisis Peran ‘Aisyiyah Wilayah Gorontalo Dalam Mewujudkan Sustainable Development Goals (SDGs)
}

\author{
${ }^{1}$ Indah Wardaty Saud, ${ }^{2}$ Widya Kurniati Mohi, ${ }^{3}$ Nurul Aini Pakaya \\ ${ }^{1}$ Program Studi Sastra Inggris,Universitas Muhammadiyah Gorontalo \\ ${ }^{2}$ Program Studi Administrasi Publik, Universitas Muhammadiyah Gorontalo \\ ${ }^{3}$ Program Studi Sastra Arab,Universitas Muhammadiyah Gorontalo \\ Gorontalo, Indonesia, 96183
}

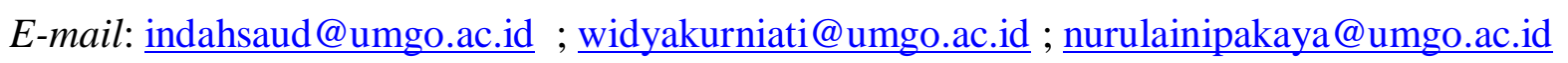

Received: 26 Februari 2020; Revised: 18 Maret 2020; Accepted: 29 April 2020

\begin{abstract}
This study aims to analyze the policies of the Muhammadiyah women's organization, Aisyiyah, in Gorontalo region in the fields of education, economics, and health in empowering women and their involvement in the global issue of Sustainable Development Goals. The research method used in is descriptive qualitative by collecting the data through interview and documentation techniques. The data are analyzed using the theory of Miles and Huberman which includes three stages namely, data reduction, display and data verification. The respondentswere determined using purposive sampling technique. The researchers interviewed the head, the secretary, and the tresure of Aisyiyah Gorontalo. Besides, the chair of the Primary and Secondary Education Assembly, Chair of the Higher Education Assembly, Chair of the Economic and Employment Assembly, Chair of the Social Welfare Council, Chair of the Health Assembly and other parties are also interviewed to strengthen the data. The results of this study indicate that the programs of Aisyiyah Gorontalo support the achievement of Sustainable Development Goals. The programs include activities to strengthen the field of public education, strengthening the economy and employment, and encourage creating health insurance for community and society.
\end{abstract}

Keywords: Role; Aisyiyah; SDGs

\begin{abstract}
Abstrak
Artikel penelitian ini bertujuan menelaah kebijakan organisasi kewanitaan Muhammadiyah, Aisyiyah wilayah Gorontalo di bidang pendidikan, ekonomi, dan kesehatan dalammelakukan pemberdayaan terhadap perempuan dan keterlibatannya terhadap isu global Sustainable Development Goals. Metode penelitian yang digunakan dalam penelitian ini yaitu kualitatif deskriptif dengan pengumpulan data melalui teknik wawancaradan dokumentasi. Pada tahapan analisis data, data ditelaah menggunakan teori dari Miles and Huberman yang meliputi tiga tahapan yaitu, reduksi data, display dan verifikasi data. Subjek penelitian ditentukan dengan menggunakan teknik purposive sampling yakni teknik pengambilan sampel dengan pertimbangan tertentu. Dalam penelitian ini, pihak-pihak yang diwawancarai antara lain ketua dan sekretaris wilayah Aisyiyah Gorontalo, ketua Majelis Pendidikan Dasar dan Menengah, Ketua Majelis Pendidikan Tinggi, Ketua Majelis Ekonomi dan Ketenagakerjaan, Ketua Majelis Kesejahteraan Sosial, Ketua Majelis Kesehatan dan pihak lain yang dibutuhkan untuk memperkuat data penelitian. Hasil penelitian ini menunjukkan bahwa terdapat program kerja Aisyiyah wilayah Gorontalo yang menunjang tercapainya Sustainable Development Goals. Program-program tersebut meliputi kegiatan penguatan bidang pendidikan masyarakat, penguatan ekonomi dan ketenagakerjaan, serta mendorong terbentuknya jaminan kesehatan bagi semua kalangan.
\end{abstract}

Kata Kunci: Peran; Aisyiyah; SDGs

Link DOI : http://dx.doi.org/10.31314/pjia.9.1.1-14.2020 


\section{PENDAHULUAN}

Aisyiyah merupakan organisasi perempuan Islam yang didirikan K.H Ahmad Dahlan dan istrinya. Organisasi ini berawal dari kelompok pengajian remaja puteri dan perempuan dewasa yang diberi nama "sopo tresno". Pendirian kelompok iniberawal dari keprihatinan KH. Ahmad Dahlan terhadap peran perempuan pada saat itu yang belum mendapat tempat layak dalam masyarakat.

Sopo Tresno belum merupakan organisasi, hanya suatu gerakan pengajian saja. Oleh karena itu, untuk memberikan suatu nama yang kongkrit menjadi suatu perkumpulan, K.H Mokhtar mengadakan pertemuan dengan KH. Ahmad Dahlan juga dihadiri oleh Fakhrudin dan Ki Bagus Hadikusumo serta pengurus Muhammadiyah lainnya di rumah Nyai Walidah. Awalnya diusulkan nama Fatimah, untuk organisasi perkumpulan perempuan Muhammdiyah, tetapi nama itu tidak diterima oleh forum rapat, (Nashir, 2016).

Haji Fakhrudin kemudian mengusulkan nama Aisyiyah yang kemudian diterima oleh forum rapat. Nama Aisyiyah dipandang lebih tepat bagi gerakan perempuan ini karena didasari pertimbangan bahwa perjuangan perempuan yang akan digulirkan ini diharapkan dapat meniru perjuangan Aisyah isteri Nabi Muhammad saw, yang selalu membantu Rasulullah dalam berdakwah. Peresmian Aisyiyah dilaksanakan bersamaan peringatan Isra' Mi'raj Nabi Muhammad pada tanggal 27 Rajab 1335 H, bertepatan 19 Mei 1917. Saat ini peran dan keberadaannya sudah banyak dirasakan perempuan-perempuan muslim di Indonesia, (Syarifuddin, 2012).

Aisyiyah berkembang pesat dan menjadi suatu organisasi wanita modern. Aisyiyah mengembangkan berbagai program untuk pembinaan dan peningkatan kapasitas perempuan dalam bidang pendidikan, sosial, kesehatan, pemberdayaan ekonomi, dan Kesejahteraan Masyarakat. Tidak ketinggalan, Aisyiyah juga ikut berperan aktif membahas isu-isu dunia seperti isu Sustainable Development Goals (SDGs). Hal ini sebagai salah satu usaha untuk mempromosikan spirit Islam berkemajuan, mengingat SDGs merupakan agenda pembangunan global yang disepakati oleh Negara-negara anggota Persyerikatan Bangsa-bangsa (PBB) termasuk oleh Indonesia pada tahun 2016.

SDGs merupakan kelanjutan dari Millenium Develpoment Goals (MDGs) yang telah berakhir di tahun 2015, yang selanjutnya difokuskan untuk mencapai tujuan pembangunan berkelanjutan yang memuat 17 tujuan dan terbagi ke dalam 169 target untuk menjadikan kehidupan manusia menjadi lebih baik. Hal Ini menjadi sejarah baru dalam pembangunan global karena perjanjian SDG di majelis umum ke-70 yang diselenggarakan oleh Perserikatan Bangsa-Bangsa bertujuan untuk mencapai pembangunan universal dan dimulai pada tahun 2016 hingga tahun 2030. Menurut Panuluh,SDGs memunculkan lima prinsip dasar yang menyeimbangkan ekonomi, sosial, dan lingkungan meliputi (1) Manusia, (2) Planet/Bumi (3) Kemakmuran (4) Perdamaian, dan (5) Kemitraan (Panuluh \& Fitri, 2016).

Aisyiyah sebagai salah satu organisasi perempuan di Indonesia berniat bahwa gerakan perempuan harus lebih luas dan memiliki peran dalam menyelesaikan masalah di Indonesia. Organisasi ini tersebar di setiap provinsi bahkan kabupaten di Indonesia dan telah menjalankan beberapa program. Djohantin sebagai kepala pusat Aisyiyah menyatakan 
bahwa SDGs erat kaitannya dengan visi perempuan (Suri, 2017). Kemudian mencoba untuk mendapatkan kesejahteraan yang setara untuk pria danwanita.

Penelitian ini tidak membahas kontribusi Aisyiyah dalam mempercepat pencapaian SGDs secara umum, melainkan dikhususkan pada usaha-usaha Aisyiyah dalam bidang pendidikan, ekonomi, dan kesehatan dimana tiga bidang ini juga merupakan tujuan dari SDGs.

Penelitian terdahulu berfungsi sebagai salah satu acuan kontent, sehingga peneliti dapat memperkaya teori yang digunakan dalam mengkaji penelitian yang sedang dilakukan. Penelitian ini dilakukan dengan mengkaji referensi maupun riset jurnal nasional dengan topik yang sesuai dengan kontribusi kegiatan Aisyiyah dalam mewujudkan SDGs. Namun dari penelitian terdahulu, penulis tidak menemukan judul yang serupa namun menemukan beberapa jurnal yang berkaitan dengan penelitian yang sedang dilakukan saat ini.

Penelitian ini juga difokuskan pada analisis dan eksplorasi perkembangan Aisyiyah di wilayah provinsi Gorontalo guna memperoleh kajian kritis terhadap dinamika organisasi ini karena belum pernah ada kajian khusus yang mengangkat peranan Aisyiyah dalam mencapai SGDs di provinsi Gorontalo.

Urgensi penelitian ini adalah sebagai dokumentasi dan evaluasi ilmiah terhadap kontribusi Aisyiyah di bidang pendidikan, ekonomi, dan kesehatan di Gorontalo sebagai upaya mempercepat tercapainya SDGs. Selama ini penelitian terkait gerakan Aisyiyah belum pernah terintegrasi dengan tujuan pembangunan berkelanjutan atau SDGs. Adapun beberapa penelitian yang pernah mengkaji tentang Aisyiyah seperti Handayaniyang menganalisis gerakan qoryah thayyibah berbasis jama'ahbisa memberdayakan masyarakat melalui pemberdayaan Copyright (c) 2020, Publik (Jurnal Ilmu Administrasi), ISSN: 2301-573X (Print), ISSN: 2581-2084 (Online)

ekonomi BUEKA (Handayani, 2016). Perubahan mencakup perubahan dari segi sosial dari yang kurang sejahtera menjadi lebih sejahtera danmandiri.

Triyono dan Mahardika meneliti Komunikasi Kesehatan pada Pimpinan Daerah Aisyiyah Kabupaten Magelang pada program Maju Perempuan Indonesia untuk Penanggulangan Kemiskinan (MAMPU) (Agus Triyono, Dzikrina Aqsha, 2018). Dari penelitian ini diperoleh hasil bahwa metode persuasif menurut Huge Rank ModelIntensive cocok diterapkan ketika menemui masyarakat yang pengetahuan kesehatan reproduksinya masih minim.

Berdasarkan penelitian-penelitian diatas, Aisyiyah telah melakukan kegiatan untuk perubahan baik dari segi ekonomi dan kesehatan masyarakat. Namun, kegiatan tersebut belum terintegrasi dengan pembahasan isu SDGs, padahal dibeberapa seminar Aisyiyah telah mengadakan rapat koordinasi maupun seminar tentang rencana kerja strategis yang mendukung SDGs. Hal inilah yang mendorong peneliti untuk melakukan analisis ilmiah terhadap kontribusi kegiatan Aisyiyah dalam mewujudkan SDGs di Wilayah Gorontalo. Adapun fokus penelitian ini adalah dibidang Pendidikan, Ekonomi, dan Kesehatan yang merupakan tiga bidang unggulan dalam organisasi Aisyiyah.

\section{METODE PENELITIAN}

Metode penelitian yang digunakan dalam penelitian ini adalah penelitian kualitatif. Metode ini diharapkan mampu menghasilkan uraian mendalam tentang suatu ucapan, tulisan, dan atau perilaku yang dapat diamati dari suatu individu, kelompok, masyarakat dan suatu organisasi tertentu dalam setting konteks tertentu yang dikaji dari sudut pandang yang utuh, komprehensif, dan holistik. 
Penulis menggunakan metode ini untuk menghasilkan data yang lengkap melalui uraian mendalam tentang apa saja program dan kegiatan yang di lakukan oleh Aisyiyah Gorontalo dalam upaya mendukung tercapainya SDGs. Selain itu, peneliti juga akan menggali informasi mengenai faktor pendukung dan penghambat yang dihadapi Aisyiyah Gorontalo dalam mencapaiSGDs.

Subjek dalam penelitian ini diambil dengan menggunakan teknik purposive sampling, dimana subjek yang terlibat diambil berdasarkan pertimbangan tertentu. Subjek merupakan narasumber yang masih aktif berkecimpung dalam organisasi Aisyiyah Gorontalo. Adapun yang akan menjadi subjek pada penelitian ini adalah ketua dan sekretaris PWA Gorontalo,Ketua Majelis Pendidikan Dasar dan Menengah, Ketua Majelis Pendidikan Tinggi, Ketua Majelis Ekonomi dan Ketenagakerjaan, Ketua Majelis Kesejahteraan Sosial, Ketua Majelis Kesehatan.

Sumber data dalam penelitian ini terbagi dalam dua kategori, data primer dan data sekunder. Peneliti menggunakan data ini untuk memperoleh informasi mengenai kontribusi Aisyiyah untuk mempercepat SDGs dan faktor pendukung serta penghambat kontribusi tersebut dalam mencapai SDGs.Sedangkan data sekunder, yaitu seperti dokumen dan sebagainya yang berkaitan dengan masalah yang diteliti. Untuk mengumpulkan data dari berbagai sumber, baik sumber tertulis maupun lisan dari para narasumber, peneliti akan menggunakan teknik pengumpulan data melalui teknik wawancara, serta dokumentasi video kegiatan Aisyiyah Wilayah Gorontalo juga akan menjadi data dalam penelitian ini.

\section{HASIL DAN PEMBAHASAN}

Dalam dokumen resmi Muhammadiyah, Pimpinan Pusat Aisyiyah merupakan salah satu anggota Pokja pada tingkat nasional untuk berpartisipasi aktif menyusun matriks-matriks SDGs dalam menentukan target-target capaian. Sebagaimana halnya struktur organisasi tertinggi, maka pimpinan wilayah Aisyiyah pada setiap wilayah diharapkan untuk berpartisipasi secara aktif dalam Pokja SDGs di masing-masing provinsi. Di provinsi Gorontalo, PWA sedang terus berusaha berkomunikasi dan bekerjasama dengan pemerintah daerah agar kebijakan dari kegiatan PWA dapat termaktub secara konkrit dalam Rancangan Kerja PWA. Sampai saat ini diakui belum ada kesepakatan secara resmi dengan pemerintah mengenai rancangan kerja yang berkaitan langsung dengan SDGs. Akan tetapi, sejak MDGs lahir PWA selalu berusaha merelevansikan kegiatannya agar dapat membantu mempercepat target SDGs di provinsi Gorontalo.Demikian halnya dengan SDGs, PWA senantiasa melakukan kegiatan yang bermanfaat yang secara langsung maupun tidak langsung dapat mendorong terwujudkan target SDGs.

\section{Kontribusi Aisyiyah di Bidang Pendidikan terhadap SDGs}

Menurut Pamungkas Alim, et al, (2018), Peningkatan kualitas sumber daya manusia adalah tugas pendidikan. Pendidikan bertujuan untuk mengembangkan kemapuan dan kepribadian manusia untuk memenuhi harapan masyarakat. Upaya tersebut dapat melalui persekolahan (pendidikan formal) ataupun pendidikan luar sekolah (pendidikan nonformal). Islam yang berkemajuan sebagaimana terlihat dari penafsiran Muhammadiyah- 'Aisyiyah 
terhadap ayat Al-Qur'an yang tidak membedakan jenis kelamin dalam hal berdakwah, menjadi karakter gerakan berkemajuan dan pentingnya pendidikan dan bagi gerakan Muhammadiyah'Aisyiyah menghasilkan pembaruanpembaruan jenis-jenis kegiatan yang dilakukan Muhammadiyah-'Aisyiyah, seperti pendidikan keaksaraan, pendirian mushola perempuan, kongres bayi atau baby show, penerbitan majalah Suara 'Aisyiyah di tahun 1926, pendirian sekolah TK, dan jenis-jenis kegiatan inovatif lain.

\section{- Mendirikan Amal Usaha Pendidikan}

Dalam Usianya yang ke 105 Tahun 'Aisyiyah yang merupakan komponen perempuan Persyarikatan Muhammadiyah telah memberikan corak tersendiri dalam ranah sosial, kesehatan, keagamaan dan terutama di bidang pendidikan yang selama ini menjadi titik tolak gerakannya. Gerakan 'Aisyiyah dari waktu ke waktu terus berkembang dan memberikan manfaat bagi peningkatan dan kemajuan harkat dan martabat perempuan Indonesia. Saat ini di usia TK ABA (Aisyiyah Bustanul Athfal) yang sudah satu abad, telah mencapai 20.125 TK. Dari satu TK di Kauman sudah berkembang menjadi 20 ribu lebih TK ABA yang menurut Menteri Pendidikan dan Kebudayaan $25 \%$ pendidikan anak usia dini di Indonesia didukung oleh 'Aisyiyah."

Bertebarannya TK ABA di pelosok Indonesia sebagai wadah pendidikan usia dini yang akan mencerahkan dan mencerdaskan bangsa. Hal ini merupakan suatu bukti bahwa 'Aisyiyah melalui mujahidah-mujahidah guru-guru TK 'Aisyiyah sudah berbuat mencerahkan bangsa dan mengabdi kepada nusa dan bangsa melalui bidang pendidikan. "Karena 'Aisyiyah apabila berbuat, apabila beramal sosial, apabila melembagakan Muhammadiyah-'Aisyiyah. Paham Islam

amal saleh bukan hanya untuk 'Aisyiyah Muhammadiyah tapi untuk memajukan bangsaNegara. Adapun Perkembangan amal usaha dalam bidang pendidikan khusunya wilayah Gorontalo menurut wawancara yang kami lakukan bersama Ibu Sekertaris Aisyiyah wilayah Gorontalo mengemukakan bahwa: "Hingga kini pada Tahun 2019 sudah didirikan 21 TK ABA dan $6 \mathrm{~KB}$ Aisyiyah yang tersebar di seluruh wilayah Gorontalo.”(HT)

TK ABA menjadi tempat pengasuhan sekaligus pendidikan anak. Jika ada masalah di rumah, koreksi pengasuhan dapat dilakukan di TK ABA. Karena jika anak tidak selesai fase golden agenya, maka potensi masalah sosial dan rehabilitasi di masa yang akan datang akan lebih berat. Menyelamatkan fase golden age berarti 'Aisyiyah sudah menyiapkan sumber daya manusia yang unggul. Dan 'Aisyiyah sudah memikirkannya satu abad yang lalu. 'Aisyiyah telah berpikir bahwa pendidikan anak menjadi hal utama bagi bangsa. Saat anak mendapatkan pendidikan yang layak dan memadai, hal itu akan menjamin masa depan sebuah peradaban. 'Aisyiyah telah berkontribusi dalam proses penyiapan keagungan keadabanitu. 'Aisyiyah telah melampaui zamannya, karena ia berpikir futuristik tentang nasib anak, terkhusus anak perempuan. 'Aisyiyah mereformasi kesadaran agar anak tidak menjadi subordinat dalam sistem sosial. Anak perempuan perlu mendapatkan pendidikan yang layak. Dengan pendidikan yang layak perempuan akan memiliki potensi yang sama dengan laki- laki.

Menilik kondisi itu, 'Aisyiyah berpikir tentang adanya kesetaraan hak. 'Aisyiyah mendorong anak-anak perempuan untuk dapat menikmati pendidikan selayaknya anak laki-laki. 'Aisyiyah telah berpikir maju melindungi hak anak yang kondisinya lebih subordinat Copyright () 2020, Publik (Jurnal Ilmu Administrasi), ISSN: 2301-573X (Print), ISSN: 2581-2084 (Online) 
dari perempuan. Tak dapat dipungkiri, bahwa 'Aisyiyah merupakan pioner pendidikan anak usia dini. 'Aisyiyah berdiri 1917 dan Frobel Kindergarten atau yang kini disebut dengan TK 'Aisyiyah Bustanul Athfal (disingkat TK ABA) berdiri pada tahun 1919. Pada masa itu perempuan masih sulit mengakses ruang publik. Mereka banyak yang dikawinkan di usia belia dan tidak banyak mendapatkan hak-haknya.

Dalam proses pendidikan anak sejak dini, 'Aisyiyah menyiapkan sumber daya manusia Indonesia yang unggul. Aisyiyah Bustanul Athfal (TK ABA) adalah jaminan masa emas (golden age). Masa itu tidak akan pernah terulang karena hanya berjalan sekali seumur hidup. Oleh karenanya mendidik anak di masa golden age menjadi investasi sumber daya manusia paling fundamental. Hal ini sejalan dengan tujuan ke empat SDGs yaitu Menjamin pemerataan pendidikan yang berkualitas dan meningkatkan kesempatan belajar untuk semua orang. bukanlah sekedar semua anak bisa sekolah, tetapi memberikan pendidikan dasar yang utuh. Karena meskipun angka partisipasi di sekolah cukup meningkat, banyak yang tidak dapat belajar dengan lancar di sekolah. Ada yang tidak naik kelas atau bahkan terpaksa berhenti.

\section{- Melaksanakan Bimbingan Teknis untuk Guru- Guru TK}

Berdasarkandata hasil wawancara dengan pimpinan wilayah 'Aisyiyahcabang Gorontalo, Moon Otoluwa mengatakan: "Dalam rangka meningkatkan kemampuan guru TK Aisyiyah Bustanul Athfal dan Kelompok Belajar Aisyiah dalam menulis/ mengarang cerita lagu serta membuat media belajar salah satunya PWA mengadakan Bimtek menulis cerita pendek bagi guru-guru PAUD di lingkungan
Asiiyah Gorontalo.” Kegiatan sebagaimana dimaksud diikuti juga oleh seluruh guruguru TK ABA Kabupaten/ Kota se Provinsi Gorontalo pada tanggal 8-10 September 2016 di Universitas Muhammadiyah Gorontalo.

\section{- Mengadakan Seminar Nasional Pendidikan}

Sebagaimana diterangkan oleh Ketua Pimpinan Wilayah Aisyiyah Gorontalo bahwa: "Pimpinan Wilayah 'Aisyiyah Gorontalo mengadakan Seminar Nasional di Wisma Lestri Gorontalo pada Tahun 2018 khususnya pada tanggal 8 hingga pada tanggal 9 September yang diikuti oleh seluruh kepala dan guru TK ABA dan KB Aisyiyah se provinsi Gorontalo hal ini dilakukan demi meningkatkan pemahaman kepala dan khususnya guru TK ABA dan $\mathrm{KB}$ tentang tata kelola PAUD. Dalam Rangka Milad 100 tahun TK ABA kali ini PWA (Pimpinan Wilayah Aisyiyah) menghimbau kepada seluruh (Pimpinan Daerah Aisyiyah) dan seluruh warga pendidikan Aisyiyah agar sekiranya berkontribusi dalam meningkatkan peneguhan warga pendidikan Aisyiyah sebagai warga muhammadiyah.

\section{- Kunjungan PWA ke TK ABA dan TK Aisyiyah}

Terkait dengan program pembangunan dunia yang juga diadopsi oleh pemerintah indonesia tentang SDGs ini, PP Aisyiyah menjadi salah satu anggota Pokja di tingkat nasional untuk berpartisipasi aktif menyusun matriksmatriks SDGs untuk menentukan targettarget capaian. Demikian juga hal nya di PWA, PWA diharapkan untuk berpartisipasi aktif dalam pokja SDGs di masing masing provinsi. Hal senada dikatakan oleh Ketua Majelis Pendidikan Dasar danMenengah: "Dalam rangka 
mendukung proses pencapaian SDGs PWA cabang gorontalo mengadakan evaluasi serta konsolidasi ke TK ABA dan KB Aisyiyah terkait program percepatan SDGs khususnya di tiga bidang Pendidikan Ekonomi serta Kesehatan”.

\section{Kontribusi Aisyiyah di Bidang Ekonomi terhadap SDGs}

Seiring dengan berkembangnya program kerja Aisyiyah dibidang Ekonomi dapat terlihat bahwa Aisyiyah telah mengupayakan program-program kerjanya sesuai dengan tujuan SDGs bidang ekonomi yakni Meningkatkan pertumbuhan ekonomi yang berkelanjutan dan inklusif; partisipasi penuh dalam pekerjaan yang produktif, jenis pekerjaan yang layak bagi semua masyarakat. Adapun aspek-aspek SDGs yang telah dilaksanakan dan relevan dengan program kerja Aisyiyah meliputi: Kerjasama Global Perluasan , Penguatan Ekonomi Dan Ketenagakerjaan Serta Terbentuknya Koperasi Simpan Pinjam Pembiyaan Syariah.

\section{- Kerjasama Global}

Sejak berdiri, Aisyiyah telah menjalin kerjasama dengan berbagai pihak baik di dalam maupun di luar negeri. Pada masa pergerakan nasional, kerjasama lebih ditujukan untuk menjalin semangat persatuan untuk perjuangan melepaskan bangsa Indonesia dari belenggu penjajahan. Pada tahun 1928, Aisyiyah menjadi salah satu pelopor berdirinya badan federasi organisasi wanita Indonesia yang sekarang dikenal dengan nama Kongres Wanita indonesia (KOWANI). Beberapa lembaga baik pemerintah maupun non pemerintah pernah menjadi mitra kerja Aisyiyah dalam rangka kepentingan sosial bersama, antara lain: Pembinaan Kesejahteraan Keluarga
Keluarga Sehat dan Sejahtera (P2WKSS), Dewan Nasional Indonesia untuk Kesejahteraan Sosial (DNIKS), Yayasan Sayang Ibu, Badan Musyawarah Organisasi Islam Wanita Indonesia (BMOIWI) dan Majetis Ulama Indonesia (MUI). Selain itu, Aisyiyah Pusat termasuk didalam Aisyiyah cabang Provinsi Gorontalo juga melakukan kerjasama dengan lembaga dari luar negeri dalam rangka kesejahteraan sosial, program kemanusiaan, sosialisasi, kampanye, seminar, workshop, melengkapi prasarana amal usaha, dan lain-lain. Diantara lembaga dari luar negeri yang pernah bekerjasama dengan Aisyiyah adalah: Oversea Education Fund (OEF), Mobil Oil, The Pathfinder Fund, UNICEF, UNESCO,WHO, John Hopkins University, USAID, AUSAID, NOVIB, The New Century Foundation, The Asia Foundation, Regional Islamicof South East Asia Pasific, World Conference of Religion and Peace, UNFPA, UNDP, World Bank, Partnership for Governance Reform in Indonesia. Kerjasama ini tetap mengutamakan dan mementingkan kondisi sosial dan budaya. Hal ini diterangkan oleh Ketua Pimpinan Wilayah Aisyiyah Gorontalo: "Sebagai organisasi perempuan yang bergerak datam bidang keagamaan dan kemasyarakatan, Aisyiyah Gorontalo telah mampu menunjukkan komitmen dan kiprahnya untuk memajukan kehidupan masyarakat khususnya dalam pengentasan kemiskinan dan ketenagakerjaan dengan melihat kondisi sosial dan budaya Gorontalo melalui kerjasama Global".

Hal senada dikatakan pula oleh Sekretaris Pimpinan Wilayah Aisyiyah Gorontalo bahwa untuk kerjasama Global kami di Gorontalo bergabung dengan Program kerja Pimpinan Aisyiyah Pusat dalam hal pengentasan kemiskinan yang dimulai dari peningkatan ekonomi 
keluarga disesuaikan dengan keadaan sosial dan budaya Gorontalo.

Penjelasan mengenai kerjasama berdasarkan sosial budaya dan ekonomi di Gorontalo, lebih dirincikan lagi oleh Ketua Majelis Ekonomi dan Naker: "Kebijakan Aisyiyah dalam program kemitraan setara dan memiliki visi misi yang sama dan organisasi meskipun sebagian besar program kemitraan atas inisiatif pimpinan pusat namun PWA diberikan kewenangan untuk membangun kemitraaan dengan multistakeholder di wilayah atau daerahnya. Beberapa kerjasama yang telah dilaksanakan antara lain : kerjasama dengan kementrian agama tentang ketahanan keluarga,pengelolaan zakat dan wakaf ,kerjasama dengan kementrian Koperasi tentang pemberdayaan koperasi dan usaha mikro kecil dan menengah anggota Aisyiyah Gorontalo. Kerjasama dengan otoritas jasa keuangan tentang pengembangan keuangan syariah, peningkatan literasi keuangan , dan perlindungan konsumen di sektor jasa keuangan. Program yang dikerjasamakan adalah LKSM ( Lembaga keuangan Syariah Mikro).

Pada tingkat regional maupun internasional pimpinan organisasi Aisyiyah mengikuti kegiatan seminar internasional dan nasional maupun konfrensi untuk memperkenalkan kerja- kerja Aisyiyah atas berabagi isu. Beberapa konfrensi yang diikuti oleh PWA antara lain : konfrensi perdamaian, konfrensi perempuan tingkat Asia Pasifik, konfrensi pengalaman baik Aisyiyah dalam SDGs di Bangkok. Sebagai organisasi perempuan yang bergerak datam bidang keagamaan dan kemasyarakatan, Aisyiyah telah mampu menunjukkan komitmen dan kiprahnya untuk memajukan kehidupan masyarakat khususnya dalam pengentasan kemiskinan dan ketenagakerjaan. Dengan visi
"Tertatanya kemampuan organisasi dan jaringan aktivitas pemberdayaan ekonomi keluarga untuk meningkatkan kesejahteraan masyarakat", Majelis Ekonomi Aisyiyah bergerak memberdayakan ekonomi rakyat kecil dan menengah serta mengembangkan ekonomi kerakyatan. Hal ini menunjukan bahwa Program Aisyiyah sudah terkoneksi dengan percepatan pencapaian SDGs Utamanya bidang kerjasama ekonomi Regional.

\section{- Penguatan Ekonomi Dan Ketenagakerjaan}

Misi majelis ekonomi adalah melahirkan pelaku usaha/wirausaha yang siap bersanding di era global,membangun kekuatan ekonomi keluarga,membangun kedaulatan pangan dan menjadikan koperasi sebagai pendukung gerakan ekonomi 'Aisyiyah. Adapun pelaksanaan prioritas Program bidang ekonomi meliputi berbagai usaha peningkatan ekonomi keluarga. Hal ini dijelaskan oleh Sekretaris dan Ketua Pimpinan Wilayah Aisyiyah Gorontalo: "Penguatan gerakan pemberdayaan perempuan melalui pengembangan kelompok BUEKA (Bina Usaha Ekonomi Keluarga Aisyiyah) seperti pelatihan pembuatankarawo dan pelatihan pembuatan Bross.hal ini bertujuan meningkatkan keterampilan ibuibu aisyiyah dalam bidang kewirausahaan". "Ya, benar kami memiliki program pengembangan ekonomi keluarga yang bekerjasama dengan dinas perindutrian dalam rangka menigkatkan usaha kecil menengah Aisyiyah".

Pemberdayaan

perempuan merupakan upaya untuk mewujudkan kesetaraan peran, akses, dan kontrol perempuan dan laki-laki di semua bidang pembangunan. Program - program pemberdayaan perempuan yang dilakukan 
oleh Aisyiyah selama ini merupakan upaya untuk senantiasa mewujudkan tercipatanya dan terdistribusinya manfaat pembangunan bagi laki- laki dan perempuan secara berimbang. Berbagai langkah dapat dilakukan untuk menciptakan kesetaraan laki-laki dan perempuan atau kesetaraan gender, antara lain dengan mengembangkan kewirausahaan keluarga sehingga dapat terwujud peran yang seimbang antara laki-laki dan perempuan dalam keluarga untuk bersama-sama membangun dan mengembangkan perekonomian keluarga demi mencapai kesejahteraan keluarga. Hal ini diungkap oleh Majelis Ekonomi dan Naker: "PWA Gorontalo memiliki program unggulan yakni pemberdayaan perempuan dalam rangka kesejahteraan Gender. Perempuan berhak untuk mendapatkan pendidikan dibidang ekonomi agar mampu menopang perekonomian keluarga melalui ekonomi kreatif yang sedang berkembang sesuai potensi daerah, kalau digorontalo usaha ibu- ibu yang berkembang adalah kerrawang atau karawo dan Aisyiyah mendukung bahkan memfasilitasi hal ini".

$$
\text { Aisyiyah Gorontalo sebagai }
$$

komponen perempuan Persyarikatan

Muhammadiyah yang bergerak dibidang sosial keagamaan telah menunjukkan kiprahnya untuk pencerahan, pemberdayaan, dan kemajuan yang memberikan kemaslahatan bagi umat sebagai manifestasi dakwah amar ma'ruf nahi mungkar. Salah satunya yakni program QoryahThayyibah,yakni perempuan yang ada disebuah desa didampingi untuk mengembangkan kewirausahaan keluarga agar bisa mandiri dalam bidang ekonomi. Ketika ekonomi mereka baik maka, secara otomatis tingkat pendidikan, kesehatan dan kesejahteraanpun akan meningkat.

BUEKA yang dilaksanakan oleh Aisyiyah Gorontalo merupakan program pemberdayaan ekonomi ummat melalui penguatan ekonomi keluarga. Masyarakat bawah sering menjadi korban kebijakankebijakan pemerintah maupun kebijakan global disebabkan lemahnya pengetahuan dan jaringan masyarakat dalam mengembangkan usaha, bahkan kadang usaha-usaha yang dilakukan masyarakat bawah menjadi sasaran para tengkulak dan pemilik modal untuk dieksploitasi.Padahal jika masyarakat memiliki pengetahuan dan jaringan usaha yang bagus, akan mengurangi problem ekonomi pada tingkat keluargamaupun masyarakat. Ditengah problem inilah Aisyiyah dengan potensi ditingkat cabang dan ranting memiliki peran strategis untuk mengembangkan usaha rakyat, selain sebagai sarana dakwah juga dapat membantu masyarakat bawah dalam meningkatkan usaha-usaha ekonomi. Dapat dikatakan bahwa Hal ini menunjukan bahwa Program Aisyiyah sudah sesuai dengan percepatan pencapaian SDGs Utamanya bidang Penguatan Ekonomi dan Ketenagakerjaan.

\section{- Terbentuknya Koperasi Simpan} Pinjam Pembiyaan Syariah

Usaha untuk mensejahterakan warganya terus diupayakan oleh 'Aisyiyah, salah satunya dengan mendorong pembentukan koperasi bagi dan oleh warga 'Aisyiyah. Aisyiyah Gorontalo menggelar "Pelatihan Pengelolaan dan Pendirian Koperasi yang Berbadan Hukum. PWA Gorontalo mendirikan koperasi yang berbadan hukum agar kita bisa mengakses bantuan juga modal sehingga nantinya bisa meningkatkan kesejahteraan para anggota Melalui pelatihan ini diharapkan Aisyiyah Gorontalo dapat memilih bentuk koperasi yang sesuai dengan kegiatan usaha yang telah mereka lakukan. Diharapkan nantinya melalui koperasi yang akan terbentuk ini dapat meningkatkan skala usaha kegiatan BUEKA dan para anggotanya karena dari 
koperasi ini bisa membantu pemasaran juga simpan pinjam. Aisyiyah Gorontalo dan UKM sendiri sangat mengapresiasi semangat dan kegiatan yang sudah dilakukan oleh kader 'Aisyiyah dan menyampaikan dukungannya agar para perempuan giat berkoperasi. Hal ini dijelaskan oleh Pimpianan Wilayah Aisyiyah Gorontalo baik ketua maupun sekretaris. "Dengan prinsip kekeluargaan, spirit dari anggota untuk anggota, melalui koperasi kita bisa melakukan upaya kolektif untuk meningkatkan kesejahteraan para anggota, 'Aisyiyah Gorontalo juga mendorong koperasi yang dibentuk oleh anggotanya telah berbadan hukum. Kebetulan di Aisyiyah Grontalo banyak dikembangkan tabungan, simpan pinjam tanpa jasa kami ingin mengelola kegiatan tersebut dengan lebih baik

Koperasi yang didirikan oleh Aisyiyah tak perlu dilabeli syariah karena tidak ada unsur riba. Sifat taawun menjadi dasar utama koperasi berdasarkan $\mathrm{Al}$ Maidah ayat 2 Aisyiyah tidak perlu ragu mengenai hukum ketika sudah aktif di koperasi Aisyiyah. Hasil analisis dari Alquran dan hadits telah diputuskan bahwa tidak ada unsur riba dalam koperasi. Tambahan pembayaran dalam simpan pinjam dilakukan bersama antara lembaga dan anggota yang bersifat taawun yang menjadi dasar utama koperasi berdasarkan Al Maidah ayat 2 Dengan demikian tidak perlu ragu terkena hukum riba. Hal ini menunjukan bahwa Program Aisyiyah sudah terkoneksi dengan percepatan pencapaian SDGs Utamanya bidang Kemandirian Ekonomi Masyarakat.

\section{Kontribusi Aisyiyah Di Bidang Kesehatan TerhadapSDGs}

Di bidang kesehatan, Aisyiyah mempunyai visi sebagai penggerak terwujudnya infrastuktur kesehatan menuju tercapainya masyarakat sehat. Hal ini termaktub dalam pembangunan dan peningkatan derajat kesehatan masyarakat dengan spirit Al Ma'un, pemberdayaan masyarakat dengan mengembangkan dan melakukan pembinaan program- program kesehatan yang bersifat promotif dan preventif di komunitas, peningktan peran Amal Usaha Kesehatan Aisyiyah untuk menjalankan fungsi pelayanan sebagai sarana da'wah bagi masyarakat khususnya kaumdhu'afa.

Di Pimpinan Wilayah Aisyiyah
provinsi Gorontalo, tim peneliti
berkesempatan mewawancarai ketua PWA, Sekretaris PWA, dan ketua majelis Kesehatan. Dalam wawancara ini,tim menggali informasi mengenai kegiatankegiatan PWA di bidang kesehatan yang bersinergi dengan SDGs. Adapun kegiatankegiatan Aisyiyah selama tahun 2015 sampai dengan tahun 2019, antara lain sebagai berikut:

\section{- Menuju Wanita Indonesia Bebas Kanker Serviks dan Payudara}

Seminar ini dilaksanakan pada tahun 2017 dan berkolaborasi dengan majelis kesehatan dan lingkungan hidup serta ibuibu dharma wanita Universitas Negeri Gorontalo. Kegiatan ini bertujuan untuk meningkatkan kapasitas anggota sebagai upaya mempercepat pelayanan akses kesehatan terhadap ibu-ibu. Selain itu, kegiatan ini juga sebagai usaha dalam mengendailkan penyakit dan penyehatan lingkungan masyarakat. Seperti pendapat informan bahwa: "Aisyiyah berupaya untuk membuat anak anak, ibu, dan remaja itu sehat. Kami mempunyai rumah sakit ibu dan anak di gunakan untuk menampung mereka yang sakit. Untuk remaja kami mensosialisasikan bagaimana cara menjauhi narkoba, pernikahan dini. Sosialisasi itu kami lakukan sebulan sekali, 
dalam pengajian, atau hari penting yang berkaitan dengan kesehatan".

Selain itu dalam mempercepat pelayanan akses kesehatan terhadap masyarakat, Aisyiyah juga mendirikan klinik-klinik di kampung, panti jompo, dan panti asuhan. Kegiatan Aisyiyah memperoleh respon yang positif dari masyarakat karena mereka merasa kegiatan tersebut sangat bermanfaat untuk menambah pengetahuan mengenai kesehatan. "Penjelasan orang tua anakanak bahwa mereka merasa puas dan akhirnya mau bergabung dalam kegiatan Aisyiyah”.

\section{- Program Perbaikan Gizi Masyarakat dan Lingkungan Sehat}

Kondisi derajat kesehatan bagi sebagian masyarakat Indonesia termasuk secara khusus kesehatan perempuan dan anak masih rendah yang disebabkan oleh berbagai faktor antara lain kemiskinan, rendahnya budaya sehat, lingkungan termasuk sanitasi yang buruk, kebijakan kesehatan belum merata, dan lainnya. Dengan kondisi tersebut berdampak pada rendahnya derajat kesehatan masyarakat dan rendahnya kemampuan memenuhi kebutuhan hidup. Dakwah 'Aisyiyah di bidang kesehatan di tingkat basis dengan spirit al-Ma'un penting untuk ditingkatkan dan diluaskan. Salah satu amal kesehatan di basis yaitu sosialisasi gizi seimbang, perilaku sehat pencegahan stunting merupakan upaya mempercepat perbaikan gizi masyarakat. Upaya ini sesuai dengan tujuan SDGs dibidang kesehatan sebagaimana hasil wawancara tim peneliti dengan informan. "Untuk memperbaiki gizi, Asyiyah bekerja sama dengan ibu-ibu PKK dan Badan Kerjasama Organisasi Wanita (BKOW) di Gorontalo, posyandu, memberikan penyuluhan dan makanan bergizi untuk ibu hamil dan anak-anak".
Masalah gizi memang menjadi salah satu isu penting yang direspon oleh Aisyiyah. Dalam Rangka pencegahan stunting dan malnutrisi. Disamping itu, Pengolahan bahan makanan menggunakan produkproduk local dan dari kebun sendiri juga disosialisasikan kepada masyarakat serta pembuatan kebun untuk peningkatan gizi dalam keluarga. "Kami sering menyampaikan dalam sosialisasi kepada ibudan anak tentang pentingnya makanan yang sehat dan bergizi, mendorong mereka agar tidak terlalu banyak mengonsumsi fast food. Aisyiyah menyarankan kepada masyarakat untuk membuat taman taman yang sehat agar lingkungan di sekitar tempat tinggal juga terpelihara".

Pentingnya gerakan masyarakat hidup sehat dimulai dari keamanan pangan. Dalam hal ini Aisyiyah senantiasa digandeng oleh pemerintah atau instantsi seperti BPOM dan juga BKOW untuk melaksanakan kegiatan yang betujuan untuk pengawasan obat dan makanan. Seperti yang disampaikan informan dalam wawancara dengan tim peneliti; "Pengawasan obat, bersama BKOW penyuluhan kepada masyarakat bagaimana penggunaan obat yang baik, konsumsi makanan yang baik bagi anak-anak. Untuk pengawasan obat dan makanan, aisyiyah menyelenggarakan Gerakan aisyiyah cinta anak, bekerjasama dengan BPOM. Aisyiyah bergerak juga berdasarkan permintaan masyarakat. Sebagian besar program aisyiyah bekerjasama dengan pemerintah."

\section{- Menyelesaikan Pembangunan} Rumah Sakit Ibu dan Anak

Rumah Sakit Ibu dan Anak Siti Khadijah Provinsi Gorontalo yang terletak di Kota Gorontalo. Rumah sakit ini melayani pasien baik dari Kota Gorontalo maupun dari luar daerah karena merupakan 
jenis rumah sakit umum. Rumah Sakit Ibu dan Anak SITTI KHADIJAH menerima pasien-pasien untuk disembuhkan dengan dukungan dokter ahli dan perawat berkualitas. Pelayanan juga berkualitas dengan alat-alat medis yang modern dan lengkap. Terdapat kamar rumah sakit bagi pasien rawat inap. Jam jenguk pasien Rumah Sakit Ibu dan Anak SITTI KHADIJAH juga diatur dengan baik agar pasien baik anak dan dewasa dapat istrahat maksimal.

RSIA Siti khadijah terus berkomitmen meningkatkan kualitas pelayanan untuk masyarakat terutama untuk ibu dan anak dengan meningkatkan pembangunan infrasturktur dan penyediaan fasilitas alatalat kesehatan yang memadai agar memperoleh nilai akreditasi yang lebih baik. Tahun 2019 ini, RSIA siti khadijah masih terakreditasi $\mathrm{C}$, maka sangat diperlukan dukungan atau support dari berbagai pihak khususnya warga muhammadiyah agar dapat berperan aktif memberikan bantuan. "Indikator keberhasilan dapat dilihat dari animo dan respon masyarakat ketika berkunjung dan berobat di RSIA, makanya RSIA saat ini Alhamdulillah akreditasi C".

Disamping itu, Aisyiyah juga berdakwah dalam bidang kesehatan dengan membuat jaminan kesehatan terhadap anggotanya. Dana dari jaminan kesehatan tersebut berasal dari uang iuran bulanan dari para anggota. Dengan dana tersebut, anggota yang membutuhkanbisa mendapatkan bantuan keringanan biaya pengobatan. Aisyiyah juga menginisiasi penggalangan dana social bagi anggota yang terkena musibah sakit maupun kematian."Ibu-ibu menyisihkan dana, agar bisa masuk dalam jaminan kesehatan bagi anggota. Dan saling tolong menolong lewat dana social."
- Sosialisasi dan Pemeriksaaan tes IVA

Tingginya angka kematian akibat kanker serviks di Indonesia disebabkan karena 95\% wanita tidak menjalani pemeriksaan secara dini sehingga menyebabkan keterlambatan diagnosis dari kanker serviks dan menurunkan harapan hidup wanita. Berdasarkan hasil penelitian probabilitas ketahanan hidup 5 tahun pasien kanker serviks dengan stadium 1 sekitar 70\%, stadium II sekitar 37,4\%, stadium III sekitar $12,4 \%$ dan stadium IV pada tahun kedua sudah menjadi 0. Salah satu upaya mengurangi kanker serviks yaitu dengan melakukan deteksi dini kanker serviks (Wigati \& Nizak 2017). Hal ini sejalan dengan penelitian Peirson et al, (2013), yang menjalani systematic review dari tahun 1995 sampai 2012. Hasil penelitian membuktikan bahwa deteksi dini lesi prakanker dapat menurunkan insiden kanker serviks dan menurunkan angka kematian yang disebabkan oleh kanker serviks.

Berdasarkan data tersebut, Aisyiyah menginisiasi kegiatan sosialisasi dan pemeriksaan tes IVA yang diselenggarakan di Aula RSIA Siti Khadijah Gorontalo dan dihadiri utusan PWA, PDA, dan organisasi wanita lainnya di provinsi Gorontalo. Kegiatan ini bertujuan untuk memberikan pemahaman kepada peserta tentang deteksi dini kanker serviks. Kegiatan ini sebagai wujud nyata kepedulian terhadap kesehatan perempuan dan untuk membantu terlaksananya tujuan ke 3 SDGs dalam bidang kesehatan yakni mengurangi sepertiga kematian akibat penyakit tidak menular seperti kanker serviks. Sustainable Development Goals (SDGs) Menjamin akses universi ke layanan kesehatan seksual dan reproduksi, termasuk dalam keluarga berencana, informasi, dan edukasi. 


\section{PENUTUP}

\section{Kesimpulan}

Berdasarkan uraian di atas diperoleh kesimpulan bahwa program kegiatan Aisyiyah Wilayah Gorontalo, khususnya pada bidang pendidikan, ekonomi dan kesehatan memiliki keterkaitan dengan capaian aspek-aspek pada SDGs. Kesesuaian tersebut antara lain pada bidang pendidikan terdapat relevansi program Aisyiyah wilayah Gorontalo dengan tujuan SDGs jika disandingkan dengan pembahasan Pendidikan untuk Pembangunan Berkelanjutan (PuPB).Pada tujuan PuPB yakni akses dan hak atas pendidikan dasar yang berkualitas, hal ini juga sejalan dengan konsep tujuan lembaga pendidikan Aisyiyah. Pada bidang ekonomi program kerja Aisyiyah wilayah Gorontalo turut bersinergi dalam pemberantasan kemiskinan yang merupakan aspek capaian dari SDGs dan pada bidang kesehatan Aisyiyah wilayah Gorontalo turut serta dalam mendorong jaminan kesehatan bagi semua umur.

\section{Saran}

Dalam penelitian ini perlu dipikirkan bersama bagaimana menjaga komitmen dari Aisiyah khususnya dalam bidang pendidikan, kesehatan dan ekonomi dalam rangka ikut berkontribusi dalam pencapaian tujuan SDGs, sehingga peran Aisiyah tetap nyata dan akan bermanfaat di tengah masyarakat.

\section{Ucapan Terimakasih}

Tim Penulis menyampaikan terimakasih kepada Majelis Dikti Litbang PP Muhammadiyah yang telah menjadi sponsor dalam pendanaan hibah untuk kegiatan penelitian ini, semoga hasil penelitian ini dapat menjadi tambahan referensi bagi PP Muhammadiyah dalam mendukung pencapaian SDGs.

\section{DAFTAR PUSTAKA}

Agus Triyono, Dzikrina Aqsha, M. (2018).

Komunikasi Kesehatan Pimpinan

Daerah ‘ Aisyiyah Dalam

Implementasi Program Mampu. In

URECOL University Research

Colloquium (pp. 295-305).

Handayani, P. (2016). Usaha

Pemberdayaan Perempuan Melalui

Pengembangan Kabupaten Sidoarjo.

In Proceeding Seminar Nasional

Ekonomi dan Bisnis FEB UMSIDA

(pp. 383-393). Retrieved from file:///E:/ARTIKEL-

ARTIKEL/SDGs/Puspita_383-393

fix.pdf

Nashir, H. (2016). Muhammadiyah Gerakan Pembaharuan. Suara Muhammadiyah.

Pamungkas, A. H., Sunarti, V., \& Wahyudi, W. A. (2018). Peran PKBM dalam Peningkatan Pertumbuhan Ekonomi dan Kesejahteraan Hidup Masyarakat Sesuai Target SDGs. SPEKTRUM: Jurnal Pendidikan Luar Sekolah (PLS), 1(3), 301-307.

Panuluh, S., \& Fitri, M. R. (2016). Perkembangan Pelaksanaan Sustainable Development Goals (SDGs) di Indonesia. www.infid.org. Retrieved from file:///E:/ARTIKELARTIKEL/SDGs/Briefing_paper_No _1_SDGS_-2016-Meila_Sekar.pdf

Peirson, L., Fitzpatrick-Lewis, D., Ciliska, D., \& Warren, R. (2013). Screening for cervical cancer: a systematic review and meta-analysis. Systematic reviews, 2(1), 35.

Suri. (2017). 'Aisyiyah Gelar Semiloka dan Diskusi Perkuat Peran Aisyiyah dalam Pencapaian SDGS.

'AISYIYAH; Gerakan Perempuan Copyright (c) 2020, Publik (Jurnal Ilmu Administrasi), ISSN: 2301-573X (Print), ISSN: 2581-2084 (Online) 
Muslim Berkemajuan, p. 1. Retrieved from http://www.aisyiyah.or.id/id/berita/ais yiyah-gelar-semiloka-dan-diskusiperkuat-peran-aisyiyah-dalampencapaian-sdgs.html

Syarifuddin. (2012). Peran Ranting 'Aisyiyah Dalam Pendidikan Islam di Karangasem Laweyan Surakarta Tahun 2005-2010. Universitas Muhammadiyah Surakarta.

Wigati, A., \& Nisak, A. Z. (2017). Peran Dukungan Keluarga Terhadap Pengambilan Keputusan Deteksi Dini Kanker Serviks. Indonesia Jurnal Kebidanan, 1(1), 12-17. 